\title{
Developing Engineers as Project Managers: An Ongoing Challenge
}

\author{
D. Kruger ${ }^{1 *}$, K.A. Legoabe ${ }^{2}$ \\ ${ }^{1}$ PrEng, Senior Lecturer, Department of Civil Engineering Science, University of Johannesburg \\ ${ }^{2}$ Post-Graduate Student, School of Engineering Management University of Johannesburg
}

*Corresponding Author: D. Kruger, Pr Eng., Senior Lecturer, Department of Civil Engineering Science, University of Johannesburg

\begin{abstract}
Engineers function optimally when using their specialized knowledge of the natural sciences together with the appropriate technology and associated hardware to address the challenges and needs of society. Engineering designs and the implementation of such designs are most often done in the format of a project or a portfolio of projects to ensure effective and efficient completion. To successfully implement such a project, it is essential that a skilled project manager should assume responsibility for planning, organizing, budgeting, scheduling, recruiting, directing, regulating, and closing it. It is clear that the success of any project may be greatly influenced by the competency and skills of this project manager.
\end{abstract}

Over the years, engineers have often been tasked with, in addition to their engineering role, assuming the role of the project manager to implement or oversee the implementation of their designed solutions. With the everincreasing complexity of multi-disciplinary, highly technology-based projects associated with the 4th Industrial Revolution, this dual role challenge has become even more daunting, especially when also having to carefully incorporate the environmental, social, labour, economic, and sustainability considerations.

Unfortunately, it is true that many projects fail or come close to failure because of inadequately trained or incompetent project managers and their project teams. Inadequate communication, unclear objectives, improper planning, scope creep, not understanding the dynamics of the project, and financial mismanagement are often cited as some of the main reasons for project failure. Well-known examples of recent failed or close to failure high-profile projects include the yet to be completed, but already billions of US\$ over-budget and years behind schedule, Kusile and Medupe power stations in South Africa (Moloi 2018), the environmental, catastrophically failed Deep-Horizon project in the Gulf of Mexico, and the controversial Millennium Dome project in the UK (Abbasi et al 2013).

This paper investigates and discusses the specific skills, knowledge, and values that an engineer should possess, and then focuses on how these competencies should be developed for the engineer to also be an effective and successful project manager in today's complex, multi-disciplinary world.

Key words: Project Management, Education, Training, Engineering skillset, Competency requirements.

\section{INTRODUCTION}

\subsection{Background}

Engineers, by their very inquisitive nature and excellent discipline-focused training, are naturally good problem solvers. They can think inside, outside, above, and below the box. Engineers regard problems as mere riddles to be solved using their intuition, their understanding of the natural and engineering sciences, and their practical experience. However, regardless of the years of experience and schooling, numerous engineers who are moved into the role of project manager often tend to focus more on the technical issues related to their engineering background, giving the project-related professional and management skills less credence (Baca 2007). Engineers who are not trained or experienced enough to fully deal with the intricacies of project management may fall short in delivering the specified project outcome by missing timeline, budget, and/or the required outcome specifications. Various authors have, over the years, argued that the required skill-set of the project manager should include peoplemanagement skills, communication skills, team-building skills, contract administration skills and negotiating skills, together with a good understanding of occupational health and safety requirements, 
contract and procurement management, risk management, ethics, professionalism, and knowledge of relevant contemporary issues (Mohan et al 2010 \& Steyn et al 2016). Under normal career development conditions, an engineer will only fully develop this skill-set and get to practise the fundamentals of management when he or she becomes accountable for the work of other people in a team, and has to guarantee that work is planned and achieved as per specified requirements. Team members being managed at this level may not all be within the same technical discipline as the engineering project manager, resulting in the project manager facing the added difficulty of understanding and dealing with other disciplines and novel factors and ideas associated with the multidisciplinary nature of the project (Faulkner \& Wearne 1980).

Steyn reiterated that project management originally developed from within the engineering industry with the construction, aerospace, and defence industries contributing significantly to this development and, as such, project management is still very much part-and-parcel of the work of most engineers in all parts of the world (Steyn et al 2016). It has been shown that people initially qualified as engineers are amongst the largest source of top executives of UK companies, and one survey indicated that more than $50 \%$ of engineers classified themselves as employed in managerial positions (Engineering Council (UK) 2001). It is thus clear that the development of an engineer's skills and expertise in management is of crucial importance.

A survey done by Faulkner and Wearne (1980) during the late seventies amongst chartered engineers in the United Kingdom, which was followed up with a similar survey in 2002 by Dudman and Wearne (2003), clearly indicated how underprepared young engineers were for future managerial tasks. The surveys also emphasised that these managerial skills are often already required early in the engineer's career, leading to the challenge of adequately developing these skills as soon as possible. Franklin (2012) also highlighted the need for accelerating the development of the professional and managerial skills of young engineers, and his findings indicate the need for more formal and sustained development of these skills amongst young engineers.

In 2014, The Engineering Council of South Africa (ECSA) added to their existing list of outcomes required from all engineering graduates graduating from South African engineering schools; a specific engineering management-related outcome which specifically reinforces and expands on the existing set of management outcomes. The original set of outcomes required engineering graduates to demonstrate competency in professional and general communication, understanding of the impact of engineering activity (sustainability), show capability of working as a team in a multidisciplinary environment, understand the importance of lifelong learning, and to understand the compliance to professional ethics. The 2014 added outcome clearly requires graduates to, over and above the previous set of outcomes, also demonstrate knowledge and understanding of engineering management principles and economic decision making in order to manage projects in multidisciplinary environments (ECSA 2014). Working alongside ECSA, the South African Council for the Project and Construction Management Professions (SACPCMP) was established in 2002 as a further regulatory body to advise on and accredit project management training, to register project management professionals, and to foster continued professional development amongst project and construction management professionals (SACPCMP 2000).

\subsection{Aims and Objective of this Paper}

As early as 1987, Thornberry claimed that project management was amongst the most demanding jobs in the engineering industry, mainly due to two reasons (Thornberry 1987). Firstly, it requires specialised management skills and abilities unlike those needed from a traditional functional management position. Secondly, there was hardly any training support available to those venturing into a project management position. Now, in 2019, with the increase in complex multidisciplinary and multinational projects, this statement is even more relevant. The same or even higher level of sharply honed professional and management skills are required from project managers, and although much more training support is available to not only develop but also regulate these skills, the problem of adequately developing young engineers as project managers remains an ongoing challenge for both educational institutes and employers alike.

This paper aims to draw focus to this ongoing challenge by highlighting the skills, knowledge, and values that an engineer should have, apart from the normal science and technological skill set, in order to also be an effective and efficient project manager. This 21 st century with its many interdisciplinary projects related to the 4th Industrial Revolution, will demand not only excellent engineering skills but 
also advanced professional and management skills. It is thus imperative for the engineering project manager to be well equipped to deal with the ever-increasing levels of multidisciplinary complexities, chaos, and uncertainty which are the trademarks of many of today's high-tech projects.

\section{LITERATURE REVIEW}

\subsection{Importance of Project Management in the Organization}

The ultimate success of any project is greatly influenced by the character and competency of the project manager (Ashcroft 2000). As most engineering solutions are implemented as projects, engineers often take the lead in such projects and therefore require excellent project-management skills to implement their designs and solutions successfully. Organizations also now recognise the positive effect that managing changes within the organization using project management principles can have on the success of the implementation of such changes. In the past, projects were often regarded as limited-duration endeavours that organisations used to implement changes or solutions to problems, but, currently, many organisations are constantly being managed by means of project implementation. Project management is believed to be the fastest growing form of management in the world and is therefore becoming a significant competency requirement in many organisations (Steyn et al 2016). It has been found many times that the impact of not delivering a project on time, budget overruns, or as per scope can be disastrous to an organisation (Melton 2010). It is estimated that $60 \%$ of project failures are due to the lack of a qualified project manager and, as such, Crawford (2006) highlighted the critical importance of qualified project management professionals and also pointed out that by 2006, many organizations still had little idea on what skills and personality traits were needed to help their project managers succeed. They also had no process for choosing project managers. The challenge is that Crawford's concern might still be valid today.

\subsection{The Project Manager in the Organization}

Back in 1976, Archibald (1976) argued that allocating an engineer as project manager is not an easy task due to the reason that, although the incumbent may possess the required technical qualifications, the individual may lack the skills and persona for being an effective manager. Crawford (2006) displays in Figure 1 the competency pyramid for project managers, where personal traits are refined through education, skills acquisition, and experience, resulting in workplace behaviour which is also influenced by the organisational culture as well as the team dynamics.

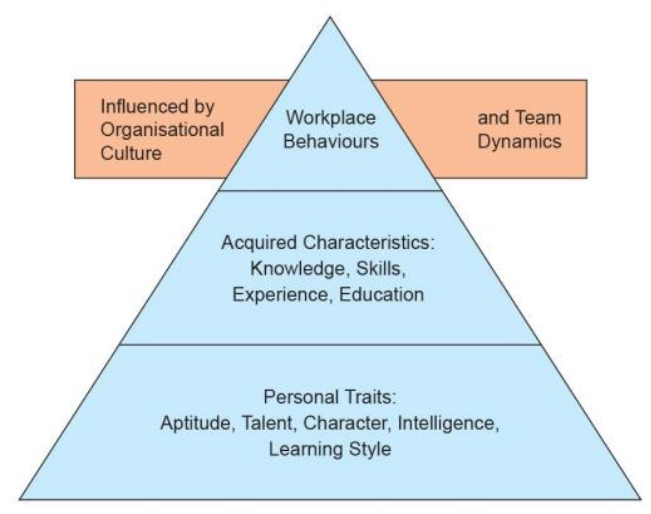

Figure1. The Competency Pyramid (Crawford 2006)

Managing a team of multidisciplinary team members in an organisation, the project manager has to keep in mind that management is not about knowing the solutions to all the questions, but about being able to ask the right questions to lead the team to the solution. Furthermore, project management is not about being a 'control freak'; it is more about understanding what control means and how to apply it efficiently within the team to ensure that all the project expectations are met (Melton 2010).

Steyn (2016) gives a clear overview of the duties of the project manager in the organization by explaining that the project manager, as a single person, assumes responsibility and accountability for the three main project constraints of project deliverable, project cost, and project schedule by heading a cross-functional team of multidisciplinary specialists, while often having to operate relatively independently from the normal chain of command, using project management methodologies. 
Kerzner (2005) summarizes the main competency requirements for project managers as: initiative, leadership abilities, ambition, creativity, flexibility and adaptability, personal commitment, vision, creating trust, ability to persuade, effectiveness, the ability to make decisions, the ability to identify problems, and the ability to organize work and delegate it to the team members.

\subsection{Engineers as Project Managers}

Engineers are trained to function effectively with ideas and hardware to address the needs and challenges of society in an effective and efficient manner by some physical process. This action is oriented largely towards the hard skills of 'things'. A dilemma an engineer might have as project manager is to avoid focusing only on these "things" or becoming mainly a specialist technical troubleshooter in a project. The engineer, as project manager, must refrain from getting trapped in giving too much attention to detailed technical problems while losing focus on the overall managerial tasks (Turner \& Williams 1985). Competent engineers often get promoted from their technical position into project and other management positions early in their careers, and in this new challenging role they will have to manage not only other engineers but also other non-technical personnel. When the engineer moves into the management sphere, the scene changes from a familiar technical environment to that of achievement of a wide set of technical and non-technical objectives, often overseeing team members from various other disciplines. Turner and Williams (1985) warned that management is primarily 'people oriented' and in order to transform an engineer into a manager, the engineer must be exposed to and acquire a new "soft" skill set, personal traits, and experience different from the usual technical speciality sphere. These authors recommended that for engineers to become competent managers, they need to get acquainted and up to speed with all the business processes and functions of the organisation, whilst still being required to maintain their engineering knowledge. Badaway (1995) pointed out that, although management theory is a science which can be taught to engineers, management practice is an art linked to not only business administration skills but, more importantly, to highly developed interpersonal skills. The American Society for Civil Engineers (ASCE) also clearly explained that the job of engineering managers includes the act of managing the engineering relationships among the management tasks related to staffing, organising, planning, financing, and the human element in production, research, engineering, and service organisations. Because of this, the ASCE highlight that engineering project managers must understand and integrate not only the technical aspects, but also the organisational, financial, external, and behavioural variables and constraints in order to accomplish the predetermined tasks and goals of the projects they manage (ASCE 2008).

\section{The Evolution of Project Management Training and Education}

During the eighties, Thornberry(1987) interviewed engineers working as project managers in hightechnology companies in the Massachusetts area about their evolution as project managers and the support training they received. Participating engineers were questioned about the type of companysponsored training programs purposely aimed at developing them as project managers for transition into their project management positions. Astonishingly, only $25 \%$ of the companies employing the engineers had any formal project management training programs, and merely a minority of this $25 \%$ of organisations engaged in a comprehensive project management training program. The bulk of the formalised programs dealt primarily with the technical aspects of project management, with very little attention given to the soft-skills requirements of management, which would include communication, leadership, decision making, stress handling, organising, and delegation skills.

Visser and his co-workers (2004) investigated the development of managerial skills in engineers. Unsurprisingly, they again confirmed that engineers are concerned with the creation of devices, systems, and structures for human use, and that their education leads them to be observant of what they see and to be a scientist of things, and not a motivator or counsellor of people. They further argued that at the start of their careers, engineers work mostly with objects and the technical aspects of their organisations. These researchers also highlighted that surveys had shown that most professional engineers are required to assume a degree of management responsibility rather early as they continue in their careers. This responsibility was often embedded in the role of a project manager, which created two challenges for the engineers. Firstly, it required management skills and abilities that are different from those required in a traditional functional management position, and secondly there was very little training support available to those engineers moving into management positions. They pointed out that for the inexperienced engineer to prepare himself or herself for management, he or she needed to obtain knowledge about management and start to develop management skills during their formal studies 
already, and that management of business organisations had to play a key role in initiating and implementing a transition model or programme to ensure that the necessary managerial training for the inexperienced engineer was put in place in order for him or her to become a successful manager. This can be a difficult process for the engineer, and to ease it and overcome resistance, a well-thought-out and intensive strategy was to be put in place by management (Visser, et al (2004).

A few years later, Thomas and Mengel (2008) investigated the then current perspectives and concepts for advanced-level project management training required for the development of the skill sets required by project managers in order for them to navigate the dynamic organisational environments and complex projects facing them. Commenting on the evolution of project management and project managers, these researchers argued that, although various international competency standards (such as those of the PMI in the USA and APM in the UK) have been developed to increase and assure the degree of professionalism of project management, the "softer" and more intuitive approaches to human activities were still very much under-represented. Their findings also indicated that there was still no recognized development path for project managers and, although the 2007 "Project Management Competency Development Framework" (PMCD) of the PMI listed a comprehensive list of skills required by project managers, the learning and development routes to acquire these skills were still not fully addressed (Cartwright \& Yinger 2007). They concluded that project management education and training require much more than the plain knowledge transfer through traditional education methods. They proposed that, for future training, the emphasis must be on training models supporting continuous change, creative and critical reflection, virtual and cross-cultural communication, coping with high levels of uncertainty and various frames of reference, increasing self-knowledge, and the ability to build and contribute to high-performance teams. Based on the PMCD, Thomas and Mengel (2008) summarized that the ultimate training goal would be for project managers to learn and practice how to lead the changes into an unknown future by surfing on the edge of chaos, while understanding and managing the risks associated with this. All of this needs to be done in a learning environment which fosters critical reflection on theory, while allowing for engagement in the practice of project management on an ongoing basis within self-organised networks of self-managing teams, while continuously empowering each other.

As stated in section 1.1 of this paper, the Engineering Council of South Africa in 2014 added a very clear and specific engineering management-related outcome required from all engineering graduates graduating from a South African engineering school. (Engineering Council of South Africa 2014). Following this, Dziekonski (2017) categorized the key competency areas of an engineering project manager into three main areas; namely: attitude, management skills, and knowledge. Table 1 lists these three areas of project manager competency, together with the operational elements associated with each.

Table1. Key competency area required from engineering project managers and the operational elements supporting each competency area (Dziekonski 2017)

\begin{tabular}{|c|c|c|}
\hline Attitude & Management skills & Knowledge \\
\hline Intellectual & Ability to make decisions & Basic managerial skills \\
\hline Creative & $\begin{array}{c}\text { Ability to assess the impact of actions } \\
\text { taken }\end{array}$ & $\begin{array}{l}\text { Experience in managing } \\
\text { projects }\end{array}$ \\
\hline Expressing confidence & & \\
\hline Assertiveness & Ability to formulate goals & Ability to use appropriate \\
\hline Self-confidence & $\begin{array}{c}\text { Ability to organise work and delegate } \\
\text { to subordinates }\end{array}$ & $\begin{array}{l}\text { project management } \\
\text { methodology }\end{array}$ \\
\hline $\begin{array}{l}\text { Authority, integrity, and } \\
\text { honesty }\end{array}$ & Ability to communicate & $\begin{array}{l}\text { Competence in the area in } \\
\text { which project is implemented }\end{array}$ \\
\hline Empathy & Ability to motivate team members & Ability to use project \\
\hline Aspiration & Ability to help in solving problems & management software Ability \\
\hline Ability to deal with stress & $\begin{array}{l}\text { Ability to focus on the goals } \\
\text { Ability to resolve conflicts }\end{array}$ & and cost of the project \\
\hline $\begin{array}{l}\text { Ease of establishing contacts } \\
\text { and forming networks }\end{array}$ & Ability to negotiate & \\
\hline Ability to work in a team & Flexible management style & \\
\hline
\end{tabular}


Dziekonski (2017) analysed these competencies and their supporting operational measures by means of a questionnaire survey amongst 751 male and female engineers acting as project managers or team members on construction projects in Poland. Using clustering as a data analysis method to aggregate objects that are more similar to objects belonging to the same cluster than objects in other clusters, the survey found that the competencies' operational elements are grouped into four clusters. Competency elements in cluster 1 included basic managerial skills, intelligence, creativity, and the ability to deal with stress, indicating that a project manager requires a combination of mental strength and organised work skills. Cluster 2 was formed by personal characteristics and interpersonal abilities such as focusing on goals, conflict resolution, and the ability to negotiate. This cluster focused on the interpersonal qualities and experience of the project manager, without which the project manager would find it difficult or impossible to efficiently perform the managerial duties in a project team. Cluster 3 was formed by emotional intelligence characteristics, which is an important competency required by project managers to recognise and deal with their own, as well as with their team members', emotions. Cluster 4 was mainly made up of the complementary elements of the competency profile, including formal project management skills (such as an ability to use appropriate project management methodology and software) which normally results from training and education. This analysis concluded that in order to fully develop the project manager, various training, education, and experience models are required, allowing for the development of the ability/skills components and attitude-related competencies found in the four clusters.

\section{DISCUSSION}

As highlighted in the literature overview above, researchers as well as professional bodies have, over many years, made it clear that engineers need to be educated and trained to achieve a wide range of competencies through a variety of studies, exposure, and experience in order to also become successful project managers. However, the recent State of Project Management Annual Survey 2018 report by Hines (2018) indicates that poorly trained project managers are still the largest project management challenge in many organisations. The question thus remains: are we stepping up to the challenge of developing engineers as project managers or are we still missing the plot? We are aware that engineers moving into the field of project management (often early in their careers) need special development attention, especially in the cluster areas 2 and 3 as described by Dziekonski (2017). Also, as per Thomas and Menger (2008), we know that the emphasis must be on training models supporting continuous change, creative and critical reflection, virtual and cross-cultural communication, coping with high levels of uncertainty and various frames of reference, increasing self-knowledge, and the ability to build and contribute to high-performance teams - all under the pressure of both time and budget constraints.

The challenge of finding a suitable model for this training and the development of engineers remains an ongoing problem. As stated, engineers are well acquainted (through their formal engineering studies) with the application of the scientific techniques in making fact-based decisions and utilising the appropriate technical resources. Engineers are also familiar with rational thought and have been trained to investigate the validity of available data and also to quantify them. As Turner and Williams (1985) speculated, part of the challenge is that engineers tend to become more fascinated by the mechanism of things, rather than by the less predictable human aspects or fuzzier financial and sustainability issues.

Interpersonal skills are possibly the most complicated area for engineers to develop. These skills are not as highly valued or seen as significant by the engineer in his/her technical role, while in the project management environment these skills are crucial. Project managers must be capable to recruit and manage team members with various personalities and backgrounds to function effectively as a loyal member of the team. This may be a very complex task for the technical-focused engineering project manager, especially when he or she is required to manage a team within a matrix organisational structure where he or she is fully accountable for project completion but lacks formal functional authority over the team members. Absence of knowledge and understanding of the softer management skills can cause an engineer to be unsuccessful in his duty as a manager. In order for an engineer to be successful in managing projects, he or she must develop himself or herself beyond virtuously technical problems and, as again highlighted by Thornberry (1987), one of the problematic areas for engineers to progress in is people skills, particularly once they progress into a project management position. For engineers to get more practical managerial experience, Visser (2004) emphasises McAlister's (1984) recommendation that the engineer or engineering student should, as early as possible, embark on various and diverse project-related assignments, volunteer their time to professional and community societies and 
committees, and expand their experience and understanding by being fully inquisitive as to the general and broader context of the tasks at hand.

In summary, it is clear that the challenge of developing engineers into good project managers remains an ongoing one, and we need to ask the question: how can we optimise the model for the training and developing of engineers into excellent engineering project managers?

\section{Case Study on a Model for Developing the Project Management Competencies in ENGINEERING STUDENTS}

When the Department of Civil Engineering at the then Rand Afrikaans University (now the University of Johannesburg) was established in 1983, project management training of engineering students was not considered a crucial component of the undergraduate degree program, and only after much deliberation and persuasion were project management semester modules included in the curriculum for both civil and electrical engineering students in the third year of study, as well as for environmental management students in their second year of study. In addition, an additional semester module on project management was included in the final year curriculum for all civil engineering students. In these modules, detailed attention was given to all theoretical knowledge areas of project management including the project life cycle, project management methodologies, project risk management, and project management software, as well as to the human, social, corporate, environmental, and legal considerations related to managing projects. In these modules, it was possible to introduce the soon-tobe engineers to both the cluster 1 and cluster 4 competencies as identified by Dziekonski (2017). However, this model still had a deficiency in that it lacked the ability to effectively cover the other range of soft skills dealing with personal characteristics, team formation, focusing on goals, conflict resolution, the ability to negotiate interpersonal abilities, and emotional intelligence characteristics as defined in the Dziekonski's cluster 3 and 4 competencies.

To deal with this deficiency of the model, the third-year module was extended to include two major group projects as integrated components of the teaching and learning process. Both these projects spanned over a full semester and were fully group-orientated with between six and ten members per group. Each group had to contain at least one member from each of the other two disciplines taking this module to ensure multidisciplinary interaction and to simulate real-life projects.

The first project was aligned with an international project done by many universities across the globe and supported by the professional societies and the engineering industry. This project led to the construction of a concrete boat by each group. These boats were to be planned, built, and raced on a date set by the concrete industry. Each group was required to form an imaginary company with a company logo, letterhead, and mission statement. The group members were to elect functional office bearers (such as the CEO and various directors) and then had to form an organisational structure within their group for managing the project. Once this structure was in place, the project team was required to develop a project proposal to be sent to industry partners for evaluation and possible support and funding. All of this was done under a strict timeline due to the fixed event date which was set for the race. In addition, no university funding was available to groups, and they were responsible for sourcing their own funds from industry sponsors. To add to the complexities of the project and elevate the project risk profile, the successful completion of the construction of the boat was a prerequisite to pass the module. All of the above allowed for competency development in both Dziekonski's second and third clusters by requiring participants to be exposed to continuous change, creative and critical reflection, virtual and cross-cultural communication, high levels of uncertainty, and the ability to build and contribute to high-performance teams, all under the pressure of both time and budget constraints.

The second project ran concurrent with the first project and was focused on community involvement. Groups had to be formed using members who were not part of the first project group, and again with a need for at least one member of each discipline participating in the module in the team. Teams again had to form a structured project team with each member being assigned a specific role in the project. Teams then had to engage with the local community -with the assistance of the university's community engagement department or the Student Representative Council - to find a suitable outreach project that they could initiate and execute successfully in the available time and within a limited budget. Apart from using the concurrently taught project management theory and methodologies, students had to develop and hone their soft skills (cluster 3 and 4 ) to successfully plan, execute, and close their group project. During both projects, regular written and oral reports were required to sharpen the communication skills of the group members. 
During the second project management module taken in the final year of study, the engineering students were required to perform group-based projects which focused on performing time and motion studies on actual construction sites, with the aim of exposing students to the real-life complexities of team performance, supervision requirements, and production control. Again, full oral and written group reports were required as part of the assessment process. To reinforce this learning experience, role-play exercises simulating on-site team performance and team conflict issues were enacted by the groups in class, with critique offered by classmates and lecturers.

The teaching and learning model followed in both project management modules, as described in this case study, allowed for both the initial development of the theoretical competency required of project managers, as well as for many of the soft-skill competencies. All of this happened in a learning environment that fostered not only critical reflection on the theory, but also allowed engagement in the practice of project management in real-life projects within groups of self-managing teams, with members continuously empowering each other.

Although the participant workload is very high when following this model (which, in fact, reflects the typical project management environment), the annual anonymous module evaluations done by participants indicated consistently that these modules were very highly scored in terms of value added, professional enhancement, interest, and enjoyment. In addition, this model continuously satisfied the various outcome requirements as set by ECSA as the professional accreditation body.

To further enhance this model, and to allow both under- and post-graduate engineering students to volunteer their time to professional and community societies and committees, a non-curricular and noncredit bearing opportunity was created for students to voluntarily join, and actively participate in, a student's society mentored by engineering staff. This society has since also become a Student Chapter of the South African Institute of Civil Engineering, and student members of the society actively plan and manage many projects. These projects include the arrangement of industry golf days, international excursions across the globe, community outreach projects, alumni reunions, formal year-end balls, and various industry networking functions (Kruger 2015). This fun learning opportunity reinforces the learning and training received in the formal credit-bearing modules, and this society has been recognized by both the local and the international engineering community, with many awards and accolades being given for its immense value to management development amongst young engineers (SAICE 2018).

\section{RECOMMENDATIONS}

It is proposed that a two-tier model is adopted for the development of project management skills in engineers. The first tier will aim to lay the foundation of this development and remains the responsibility of the universities. At least one, but preferably two, solid core semester modules in project management should be taught at undergraduate level. These modules must not only cover the theory and methodologies of project management, but must also include high-impact, hands-on group project work as per the case study described. In addition, on each engineering campus, engineering societies and student chapters should be developed and fully supported by engineering faculty mentors, and all engineering students must be encouraged to fully participate in the projects and programmes of these societies. The second tier of the model remains the responsibility of the engineering industry employing the newly-graduated engineers. Employers must play a key role in initiating and implementing a wellstructured graduate programme to ensure that the necessary managerial exposure and further training for young engineers is put in place. This graduate programme should be mentored and supported by either senior engineering project managers in the organization or by retired engineering project managers appointed on a contract basis by the employers. The outcomes associated with the first tier of this model should be assessed during the regular degree program accreditation visits by the professional bodies, whilst the second tier of the module normally would form part of the professional review process which engineers have to follow in order to register as a professional or chartered engineer with their national regulatory bodies (such as ECSA as well as SACPCMP in South Africa).

\section{CONCLUSION AND SUMMARY}

For engineers to transform into successful project managers, they must not only expand their specialised technical talents, but must also develop and obtain new business and management focus values to enhance their normally technologically oriented point of view. However, this requires time, cautious 
planning, and preparation, together with both on- and off-the-job training. Utilising the values of the engineering approach together with competency in the management of human resources, time, cost, and quality management, as well as maintaining the professional skills at an elevated level, means that engineers could turn out to be very efficient and competent project managers (Melton 2010). Visser (2004) also pointed out that engineers have learned that success will be contingent not only on their technical knowledge, but also on other factors such as administrative and personnel matters.

As pointed out by Turner in 1985 already, engineers require quality management schooling in order to accelerate, sharpen, and eventually swerve them into the latest spheres of awareness and insight into management thinking (Turner \& Williams 1985) [3]. This schooling should start during their senior years of undergraduate studies and continue while they are climbing the corporate ladder as candidate engineers. The fruitful evolution of engineers into project management and management in general is clearly related to three interconnected components; namely management skills, knowledge, and attitudes. A working knowledge and thorough understanding of these concepts, together with exposure to the philosophies and elements of each of these components, is an essential outcome required from a teaching and experiential learning model for transforming good engineers into equally good and successful project managers. Without such a well-thought-out model and considering the everincreasing complexity of multi-disciplinary high-end technology-based projects associated with the 4th Industrial Revolution, the failure rate of projects will remain unacceptably high.

To reinforce the above conclusion, one can draw parallels to an analogous training enhancement model introduced by the airline industry after the catastrophic 1977 Tenerife airport disaster, where two Boeing 747 aircraft collided, killing 583 people. This was followed shortly by the 1978 United Airline flight 173 crash when a plane piloted by an experienced crew crashed due to running out of fuel. A new training model named CRM (Crew Resource Management) was introduced by the aviation authorities and CRM training is now a mandatory requirement for commercial pilots across the world. The aim of this training is to upskill the normally very technically competent cockpit crew with the cognitive and interpersonal skills required to operate as a team, effectively and safely. CRM training focuses on knowledge, skills and attitudes required for situational awareness, leadership, flexibility, adaptability, problem solving, event analyses, decision making, communication, stress management, and teamwork (Helmreich et al 1999). In both the airline and the project management industries, all of these skills are required over and above the normal technical skills, especially when work pressure increase and failure of the task or project at hand could lead to fatalities, economic disasters, and serious social or environmental impacts.

Finally, and by extending the conclusion made by Hlophe and Visser (2018) on project management training, both training and experience play critical roles in ensuring the effective and successful execution of the project management process. Both tertiary educational institutions and workplace organisations should be prepared to commit much more effort, time, and money to developing excellent capacity in, and knowledge of, project management amongst engineers.

\section{REFERENCES}

[1] Abbasi, N \& Wajid, I \& Iqbal, Z \& Zafar, F. (2013). Project Failure Case Studies and Suggestion. International Journal of Computer Applications. 86. 10.5120/14992-2696.

[2] Archibald, R.D. (1976). Managing High-Technology Programs and Projects, New York, John Wiley and Sons, INC, pp 55.

[3] ASCE. (2008). American Society of Civil Engineers. Civil Engineering Body of Knowledge for the 21st Century, 2nd edition. ASCE report, Reston, VA, United States.

[4] Ashcroft, R. (2000). "Practical Project Management for Engineers and Technicians," IDC Techbooks, pp $1-2$.

[5] Baca, C.M. (Oct 2007). Project Manager: Who? Me? Machine Design 79(20), pp 64-65.

[6] Badaway, M.K. (1995). Developing Managerial Skills in Engineers and Scientists: Succeeding as a Technical Manager. 2nd Edition. Wiley.

[7] Cartwright, C. \& Yinger, M. (2007). Project Management Competency Development Framework, 2nd edition. Paper presented at PMI ${ }^{\circ}$ Global Congress 2007 - EMEA, Budapest, Hungary. Project Management Institute.

[8] Crawford, J. K. (2006). Why Project Managers Fail - and How to Help Them Succeed! PMI® Global Congress 2006, Project Management Institute. Seattle, United States. 
[9] Dudman, A. and Wearne, S.H., 2003, Professional Engineers' Needs for Managerial Skills and Expertise, SEMTA Report, Engineering Council (UK) and University of Manchester Institute of Science \& Technology), Summary in The Chemical Engineer. August 2003, pp 26-27.

[10] Dziekonski, K. (2017). Project Managers Competencies Model for Construction Industry in Poland. Procedia Engineering. Vol 182. pp 174-181. ISSN 1877-7058.

[11] Engineering Council (UK) (2001). Engineers for Britain - Digest of Statistics. United Kingdom.

[12] Engineering Council of South Africa. (Jul 2014). Qualification Standard for Bachelor of Science in Engineering (BSc(Eng))/Bachelor of Engineering (BEng). Document E-02-PE Rev 4.

[13] Faulkner, A. C. \& Wearne, S. H. (1980). Professional Engineers' Needs for Managerial Skills and Expertise, Technical Note, Proceedings of the Institution of Civil Engineers. Part 1, vol 68, pp 103-104.

[14] Franklin, C. Mohan, A. Merle, D. Lannin, J. \& Nair, S. (2012). Perceptions of Professional Skills by Graduate Students - A Comparative Study between Engineering, Education and Biology. International Journal of Engineering Education, Vol. 28,(3), pp 588-598.

[15] Helmreich, R.L., Merritt, A.C., \& Wilhelm, J.A. (1999). The evolution of Crew Resource Management Training in Commercial Aviation. International Journal of Aviation Psychology. Vol 9 (1), pp 19-32.

[16] Hines, V. (2018). The State of Project Management Annual Survey 2018, Wellington PPM Intelligence, United Kingdom. p 21.

[17] Hlophe, S.C., \& Visser, J.K.. (2018). Risk Management During Outage Projects at Power Plants. South African Journal of Industrial Engineering. Vol 29 (3), pp 82-91.

[18] Kerzner, H. (2005). Project Management, p 162, 9th Edition. John Wiley \& Son

[19] Kruger, D. (2015). UJ civil student society now officially a SAICE student chapter, Civil Engineering / Siviele Ingenieurswese, SAICE Magazine. Vol 23, (4), May 2015, p.74 - 75.

[20] Mc Allister, J. (1984). Why Engineers Fail. Machine Design, February, pp. 47-49.

[21] Melton,T. (2010). Asking the Right Questions, Using the Right Tools. The Chemical Engineer, Vol 824, Feb 2010, pp 40-43. Institute of Chemical Engineers, United Kingdom.

[22] Mohan, A. Merle, D. Jackson,C. Lannin, J. Nair, S. (Dec 2010). Professional Skills in the Engineering Curriculum. IEEE Transactions on Education. Vol. 53 (4). pp 562 - 571.

[23] Moloi, B.M. (2018). Managing Knowledge in Mega-Infrastructure Projects, Master's Thesis (MA), Faculty of Arts and Social Sciences, Sunscholar Research Repository, University of Stellenbosch, South Africa. http://hdl.handle.net/10019.1/105100

[24] SACPCMP (2000). Act no. 48 of 2000, Project and Construction Management Professions Act, Government Gazette, Republic of South Africa. Vol 426, No 2183, Dec 2000.

[25] South African Institution of Civil Engineering, Media Statement (Oct 2018), http://saice.org.za/saicehonours-civil-engineering-excellence-at-national-awards. (Accessed 10 April 2019).

[26] Steyn, H. et al. (2016). Project Management: A Multi-Disciplinary Approach. 4th Revised Ed. FPM Publishing, South Africa. pp. 1 -15.

[27] Thomas, J. \& Mengel, T. (2008). Preparing Project Managers to Deal with Complexity - Advanced Project Management Education. International Journal of Project Management. Vol 26 pp 304-315.

[28] Thornberry, N.E. (1987). 'Training the Engineer as Project Manager - How to Turn Technical Types into Top-Notch Project Managers. Training and Development Journal. Vol 41 (10) pp 60 -62.

[29] Turner, B.T. \& Williams, M.R. (1985) "Management handbook for Engineers \& Technologists," London Business books. pp13-15, 23, 25.

[30] Visser, H. Naude, L. \& Schepers, J. (2004). Transformation of Managerial skills of Engineers. SA Journal of Human Resource Management. Vol 2 (2). pp 17-23.

Citation: D. Kruger, K.A. Legoabe, "Developing Engineers as Project Managers: An Ongoing Challenge”, International Journal of Constructive Research in Civil Engineering, 6(3), pp. 1-10 DOI: https:// doi.org/10.20431/2454-8693.0603001.

Copyright: (C) 2020 Authors, this is an open-access article distributed under the terms of the Creative Commons Attribution License, which permits unrestricted use, distribution, and reproduction in any medium, provided the original author and source are credited. 